\title{
Opportunities and Challenges in Dairy and Future a Head
}

\author{
Madhusudana Rao* \\ Deputy Director, TSDDCF, Adilabad, India \\ *Corresponding author: Madhusudana Rao, Adilabad, India \\ Submission: 監August 29, 2017; Published: 海 December 06, 2017
}

\section{Conceptual Paper}

The dairy sector promotes vital linkages and synergies between the two pillars of the economy, namely industry and agriculture. A large part of Indian population including 70 million rural household, primarily, small and marginal farmers and land less labourers in the country are connected, either directly or indirectly, with the dairy sector. Not only does it bring immense benefits to the economy in terms of raising agricultural yields, meeting productivity targets, creating employment throughout the country, especially in the rural areas, it also has an enormous potential in contributing to the future industrial growth of the economy. Hence the rapid and coordinated up gradation of this sector attains enormous significance in India's development.

India has a unique pattern of production, processing and marketing/consumption of milk, which is not comparable with any large milk producing country. The country is the world's largest milk producer and the world's largest consumer of dairy products, consuming almost $100 \%$ of its own milk production.

Some 70 million farmers maintain about 105 million cattle, fed largely on crop residues, accounting for 98 percent of milk produced in India. Despite operation flood, which organized about 11 million farmers into 0.1 million village Dairy Cooperative societies having about 110 farmers each, this sector is highly fragmented.

The Indian dairy sector is different from other dairy producing countries as India places its emphasis on both cattle and buffalo milk. Out of all the bovine population in India, $40 \%$ are indigenous cows, $46 \%$ are buffaloes and $14 \%$ are imported European or North American cattle cross breeds. Out of the nation's total milk production, about 55\% comes from buffaloes and remainder from dairy cows.

Of the total milk produced about $50 \%$ is retained by producers for domestic consumption, leaving about $50 \%$ as marketable surplus. Of the milk traded over $50 \%$ milk is in the form of liquid milk, 35\% in the form of traditional products and the remaining is accounted for the butter, milk powder and other western type processed products. The organized sector (large scale dairy plants) processes about 13 million tones annually, while the unorganized sector (Halwaiis and Vendors) processes about 22 million tones per annum.

In the organized diary industry, the cooperative milk processors have a $60 \%$ market share. The cooperative dairies process $90 \%$ of the collected milk as liquid milk where as the private dairies process and sell only $20 \%$ of the milk collected as liquid milk and $80 \%$ as other dairy products with a focus on value- added products. Considering the still nascent levels of processing at the present, the dairy sector holds extensive potentiality.

Competitiveness both in terms of price and high quality of products, meeting international standards, will become the two most important factors in terms of determining the share of the Indian diary industry in the GDP of the country as well as of trade share internationally. In order to compete (in the domestic as well as in the global market), milk has to be produced at a competitive price. Therefore, measures to reduce costs of production have to be explored. Furthermore, with regard to quality assurance of milk, a greater emphasis on clean milk production and a reduction in the antibiotics, pesticides, and other contaminant residues in milk need greater attention. In order to achieve greater profitability, quality standards need to be improved for which the up gradation of techniques processes and machinery is necessary.

\section{Challenges Faced by the Indian Sector}

In order to face competition, wherever possible, better and newer ways of doing things need to be identified. There is a strong need to redefine the traditional methods of operation. The consumers today are increasingly becoming conscious of quality and have started to exercise their right to expect that the food they eat is safe and suitable for consumption. The manufactures can no longer take the consumers for granted and are required to assure and instill a confidence in the consumers that the products being produced by them are safe.

The international market in more demanding in terms of quality, safety and delivery. The international food laws, which have come into force, are responsible for this emphasis on quality and safety of foods. Codex is concerned with the microbiological quality 
of dairy products, and has recommended measures to minimize microbiological contamination. Codex guidelines stipulate that the raw material should be produced in a manner that minimizes bacterial load, growth and contamination. To achieve this, codex favours the Hazard Analysis Critical Control Points (HACCP) based approach to enhance food safety. This is perhaps one of the reasons why a number of nations have made HACCP system mandatory for production of dairy products. In the current scenario of the Indian dairy industry being the largest milk producer in the world, the implementation of the HACCP quality management systems would provide it a competitive edge in the international market.

The pricing policy of raw milk becomes another major challenge because currently it is based on the fat percentage in milk. This encourages milk producers to increase the measurable fat percentage by disturbing the natural composition of milk which compromises to a large extent its quality.

The prevailing hygiene conditions, especially in villages are far from satisfactory. Improvement in the quality of milk and dairy products originating at the village levels is more of a necessity now than ever before. The sanitary conditions at the village level need improvement. Food safety and sanitation are absolutely essential in assuring the production of safe dairy products.

A vigorous programs of education and training on good dairy practices could result in the production of safe dairy products, but for the programmers to succeed they have to be participative in nature. In this regard, education and training of all the employees is essential so that they understand what they are doing and develop a sense of ownership. However developing and implementing such programs in the dairy industry requires a strong commitment from the management, which at times, is a stumbling block.

The quality and food safety are activities driven from the top. The top management has to be committed to quality and safety, for things to improve. At the processors level, most of the units at present, find it difficult to confirm to HACCP standards, have poor hygienic levels and most of the operations are done manually. If the dairy industry is to survive in the ever-increasing global competition and excel in its quality and safety approach, it has to follow sound hygiene norms, good manufacturing practices, proactive food safety programs and quality management systems.

The dairies have to be designed to accommodate the safety parameters necessary for meeting international norms. There is a need to constantly train and upgrade the skills of dairymen in the new technological developments taking place around the world. The testing facilities are also oriented to only routine testing. The main emphasis is on production related testing and safety related testing such as for lead, aflatoxin, pesticide residues but there are very little or no testing facilities for pathogenic micro-organisms. It is imperative to know their presence or absence, to be able to label the product as safe or unsafe for consumption.

Similarly a commitment is required from the regulatory authorities to make HACCP, including sanitation programs, as a part of their regulations. Since such programs benefit all and sundry - may it be the manufactures, employees, suppliers, custom packers, distributors, retailers, consumers, regulatory authorities or the nation as a whole, they deserve a national generic promotion campaign to create an awareness among the public at large, of what will work as a driver for the industry.

Dairy industry in India is also unique with regard to availability of large proportion of buffalo milk. Buffalo milk is now estimated to account for $57 \%$ of the total milk production in India. Thus, India can focus on buffalo milk based specialty products, like Mozzarella cheese, tailored to meet the needs of the target consumers. Since most of the dairies produce almost similar dairy products like varieties of milk, butter, ghee, skimmed milk powder and whole milk powder, there is immense scope for the broadening of the products range through value addition including the upcoming products such as cheese, dahi, flavored milk, etc.

\section{Inconsistencies in the Indian Dairy Sector}

There are aspects of the Indian dairy industry, which make it different from the rest of the world. It's neither a very energy using industry nor a capital-intensive one! In fact, the term of feed etc. it relies on residues and by products. It is more of the subsistence kind, but it contributes very substantially to income generation in rural areas. A few of the most glaring ones are listed below:

i. India is the largest milk producer in the world but it has a very low productivity per animal. It's per animal productivity is a meager 1.5 liters per day.

ii. Strangely, in the operation flood areas the productivity per animal is 4.2 liters per day in buffaloes and 6.5 liters per day in cross-bred cows as against the national average per animal productivity of 1.5 liters per day.

iii. Despite India having doubled its milk production in the last two decades, the per capita availability at 240 grams per day is lower than the world average of 285 grams per day.

iv. Even through the per capita milk availability in India is good according to the national institute of nutrition, the actual milk intake varies from a sparse $20 \mathrm{gm} /$ day in many districts in Eastern region to almost a liter per day in Punjab.

v. According to the recent National sample survey organization (NSSO) consumer expenditure survey, all income groups in urban and rural areas reported higher expenditure on milk and milk products. Yet the low purchasing power denies consumption as per the dietary norms to a majority of Indians.

vi. During the last five years ending 2015-16, the average annual incremental production of food grain is 2.05 million tonnes. During the same period, the average annual incremental milk production was over six million tonnes. Notwithstanding its top place; dairying has not received due attention from national planners, economists, social scientists and others. For example, the investment the dairying made under the five years plans is not commensurate with its output. Consequently, its potential has not been adequately tapped. 


\section{Development and Future Outlook}

\section{Trade}

The country's milk output may increase by 4.8 per cent to 154 million tonnes assuming a normal monsoon in 2016, while domestic consumption of milk is forecast to rise by 5 per cent to 62.75 million tonnes in the same period, the US Department of Agriculture (USDA) said. "Overall dairy exports (from India) are minimal due to high domestic consumption. CY 2016 non-fat dry milk (NFDM) exports are projected to be flat at 30,000 tonnes due to uncompetitive export prices," USDA said in its report. Due to low global dairy prices and high domestic costs, India is finding it difficult to sustain exports of dairy products. On the other hand, factors such as the reintroduction of subsidies by European Union, devaluation of currency of New Zealand (a major dairy exporting country), combined with continuing global economic downturn, have made dairy imports into India attractive. It is predicted that dairy commodities will be the first large-scale imports and will be used by Indian dairy cooperatives and companies to make reconstituted milk and other branded dairy products. This may be followed by Imports of branded dairy products.

In the past, India has not been permitting free import of dairy products. As the country's dairy sector employs 90 million people, India has advocated that milk and cheese be excluded from the scope of free trade agreement under negotiations with the European Union. However, despite Indian governments fear about how small dairy farmers could suffer from import liberalization; India is now facing strong pressure to open up its market to dairy products from Europe. There are arguments suggesting that removing such tariff would leave India's farmers unable to withstand competition from European imports. Often these imports have been highly subsidized and can be sold at lower prices than domestically produced goods.

Other than the strong pressure from EU to open up its market, India's dairy sector may also become jeopardized by the proposed free trade agreement with Australia and New Zealand. India had entered into a Free Trade Agreement with South Korea and ten other countries in 2009. Currently the plan is to also reduce the tariff rate for New Zealand and Australia to encourage trade. It is feared that entering into a free trade agreement with Australia and New Zealand is far lower than in India due to their pastoral system. In contrast, in India dairy animals are raised by concentrate feed and fodder, therefore the cost of production is much higher.

\section{Supply and demand}

A recent survey has revealed that on average, an India family allocates 17 percent of the household food expenditure on milk and milk products, with rural families allocating 15 percent and families in the urban area allocating over 18 percent. As income continues to increase, it is predicted that the demand for milk is going to rise faster that seen in the previous decade. Moreover, the overall demand is growing rapidly compared to milk production. The high GDP growth rate, enhance income of rural households and the farm debt waiver are influencing the demand for milk both in the rural and urban areas.

Apart from the rapidly increasing demand for milk and dairy products, other reasons such as the increased cattle feed cost and low availability of dairy farm labour in the rural areas have also resulted in increase in the cost of production. It is estimated that the demand for milk will grow at $7 \%$ per annum at current rate of income growth, while growth in milk production is likely to continue at the present rate of $4.4 \%$ in the near future.

A few suggestions to the future development of India's dairy industry have been proposed:

i. Production Cost Reduction: In order to increase the competitiveness of Indian dairy industry, efforts should be made to reduce cost of production. This can be achieved through increasing productivity of animals, improve health care and breeding facilities and management of dairy animals. The Government and dairy industry will need to play a vital role in this direction. The cash incentive given by a few governments to its milk producers such as Karnataka and Telangana is not a permanent remedial measure to bring down the cost of production. The implementation of Ration Balancing Program in true spirit is also a ray of hope for decline in cost of production.

ii. Strategy and Infrastructure Development: Indian dairy industry should further develop proper dairy production, processing and marketing infrastructure, which is capable of meeting international quality requirements. A comprehensive strategy for producing quality and safe dairy products should also be formulated with suitable legal backup.

iii. Focus on specialty Products: Dairy industry in India is unique with regard to the availability of buffalo milk. In this case, India can focus on buffalo milk based specialty products, such as Mozzarella cheese, in order to meet the needs of the target consumers. Further, buttermilk, lassi in the powder form to make available as ready to drink have got demanding consumer acceptance.

Notwithstanding, these contradictions, the Indian dairy sector is vibrant with an exciting future. With the onset of GST, the prices of a few milk products will come down paving path for more market. As India enters an era of economic reforms, agriculture, particularly the livestock sector, is positioned to be major growth area. It is increasingly being recognized that dairying could play a greater constructive role in promoting rural welfare and reducing poverty. 